WHO Expert Committee on Gonococcal Infections. Report of First Meeting. 1962. WHO Technical Report Series No. 262. Pp. 70. (5s.)

In its fifth report (1960) the WHO Expert Committee on Venereal Infections and Treponematoses recommended that the WHO should show an active interest in all aspects of the world-wide public health problem of gonococcal infection and that the necessary intensified research should be included in the WHO research assistance programme. The present report records the proceedings and recommendations of the first meeting of the WHO Expert Committee on Gonococcal Infections, which was held in Geneva during November, 1962. This valuable report should be read by venereologists and all others interested in the difficulties which have so far prevented progress in controlling this widespread and prevalent venereal infection.

S.M.L.

Proceedings of the XII International Congress of Dermatology, held in September, 1962, at Washington D.C. 1963. Excerpta Medica Foundation, Amsterdam.

The XII International Congress of Dermatology held in Washington D.C. in September, 1962, was attended by 2,301 members from 69 countries. The proceedings of the congress have now been published in two large volumes, which present a detailed picture of recent progress in the medical and scientific aspects of dermatology and venereology. Many of the review articles are of high standard and provide an excellent opportunity of keeping abreast with knowledge in several fields. As might be expected, the original contributions are more variable in quality, but examination of the reports will demonstrate the wide range of research activities which are now being carried on all over the world. The areas of common ground between dermatology and venereology are still very considerable and those who devote all their time to the study and treatment of the venereal diseases will find much that is instructive and helpful in the sections dealing with dermatological matters.

The section concerned with treponemal diseases and non-treponemal venereal diseases, including gonorrhoea, in the second volume, includes papers on the epidemiology of the treponematoses, on clinical, laboratory, and therapeutic problems, and on trichomoniasis, and there is a series on problems in the diagnosis and treatment of gonorrhoea. The major part of the discussion which followed is also recorded.

The standard of printing, binding, and reproduction of photographs is very high and the volumes will form a useful addition to a comprehensive medical or departmental library.

R.D.C.

\title{
OBITUARY
}

\section{MARY MICHAEL-SHAW, 1897-1963}

Born on January 31, 1897, Mary Michael entered the London School of Medicine for Women in 1914, qualified with the conjoint diploma in 1922 and graduated M.B., B.S., in 1923. She was appointed house surgeon at the Royal Free Hospital and later held a house surgeon's appointment at the Lock Hospital where she started to gain experience of the subject to which she devoted her professional life.

She and her architect husband later went to Kenya where she became the medical officer in charge of child welfare and venereal diseases. In 1933, after some 5 years abroad, they returned to England and Dr. Michael-Shaw was appointed to the Venereal Diseases Department at the Royal Free Hospital. In 1938 she became Director of the Department, taking over on Dr. Margaret Rorke's retirement, and continued to administer this department until her own retirement in March, 1958. During these years she was appointed Teacher in V.D. in the University of London.

In 1939 she was appointed Medical Officer in Charge of the Special Clinic at the Salvation Army
Mothers' Hospital in Clapton, a position which she held for 3 years. Her articles published in the Daily Mirror early in the second world war, first brought to the attention of the general public the rising incidence of V.D. and the dangers thereof. Shortly after the articles appeared, she was asked to join the Ministry of Health as part-time assistant to Col. L. W. Harrison, where the women's clinics became her special responsibility. She helped to put the venereal diseases into proper perspective and worked hard to encourage her patients to understand more about their disease and to face the future without the terrible sense of guilt which oppressed so many of them. She had considerable knowledge of prevailing social conditions and her interest in her patients extended well beyond the clinic walls. Many of them had reason to be grateful to her for her kindness and practical help. She was particularly interested in the problems of syphilis in pregnancy. Always ready with pertinent advice, both medical and otherwise, she was a member of the committee which ran the Highbury Hostel for unmarried 
mothers, a hostel attached to the Royal Free Hospital for girls and women requiring treatment for V.D. during pregnancy. All the patients were confined in the wards attached to the V.D. Department until the hostel closed in 1952.

Dr. Michael-Shaw was an active supporter of the Medical Society for the Study of Venereal Diseases. a council member, and during the session 1950-51 President of the Society, when she gave her presidential address on the subject of "Congenital Syphilis". She was also a member of the Venereologists' Group Committee of the B.M.A.

After the end of the war, in 1945, she visited V.D. clinics in Germany in her official capacity; the conditions she found were sometimes far from satisfactory and she was able to advise and help in her experienced and tactful way. As a result of her visit, several German venereologists came to Great Britain.

One of her great interests was the collecting of antique medical books, many of which were of particular interest to her as they dealt with her special subject. It is a matter of regret that this collection was dispersed when she retired.

Dr. Michael-Shaw was a devoted wife and mother and latterly very much enjoyed the company of her grandchildren. She died unexpectedly after an operation on October 28,1963 . The sympathy of her friends and colleagues goes out to her family.

J.S.

\section{ROMAN ATLAS, 1910-1963}

Dr. Roman Atlas died suddenly on December 24, 1963, at the age of 53 years. Born in Lwow (Poland), he graduated in 1934 and proceeded M.D. (Lwow) in 1938. He was interested in gynaecology, but in 1939, when war came, he joined the Polish Army in exile and with it came to England in 1940. He then transferred to the Royal Army Medical Corps and saw service in Great Britain, West Africa, India, and Belgium, becoming a graded specialist in venereal diseases. During the war our paths never crossed, but on several occasions I heard his name mentioned as a fellow venereologist in R.A.M.C. messes. In fact he replaced me at the British Military Hospital in Lucknow and after the war I succeeded him as clinical assistant at the Whitechapel Clinic of the London Hospital. It was not until 1950, however, that we finally met in the Department for Venereal Diseases at University College Hospital. In 1951 he was appointed assistant physician to the department for venereal diseases of the Prince of
Wales's Hospital, Tottenham, and there he remained until his untimely death.

He loved medicine, was a very able clinician, and took a particular interest in the social aspects of his specialty. He regularly attended meetings of the Medical Society for the Study of Venereal Diseases. He was always frank and said what he thought; brisk of movement and in temperament he was full of energy and down-to-earth humour, all of which made his sudden death the more unexpected. His outside interests were wide and revealed him as a man of culture; he loved the theatre, music, and literature, was a numismatist and a cactus-fancier. A proficient linguist, he travelled extensively on holidays and regularly attended medical meetings abroad.

He took a great pride in his lovely home and was a devoted husband and father. He had many friends within and outside the profession who will miss him and our deepest sympathy goes out to his widow and two young daughters. 